\title{
Arroubos econômicos, legitimação política: uma análise da moratória da dívida externa de 1987
}

\author{
Economic raptures, political legitimacy: \\ an analysis of 1987 foreign debt moratorium
}

IVAN COLANGELO SALOMÃO

PEDRO CEZAR DUTRA FONSECA*

RESUMO: O contexto histórico em que José Sarney assumiu a Presidência da República respondeu por um dos principais motivos de sua fragilidade quando da ascensão ao cargo. Inserido no momento histórico do ocaso do regime militar, o presidente eleito na chapa oposicionista colheu a hostilidade das ruas e a indiferença do establishmet político. Ciente de que não contaria com o apoio da classe política nem da sociedade brasileira, Sarney tratou de fazer das medidas econômicas de ampla repercussão popular seu principal veículo de legitimação. Após a sucumbência do Plano Cruzado, o presidente tratou de fazer da negociação da dívida externa sua principal bandeira política, tendo pretendido, através do tom ufanista em que a envolveu, angariar o apoio interno de que tanto necessitava.

PALAVRAS-CHAVE: Dívida externa; Moratória; José Sarney; Legitimidade

ABSTRACT: The historical context in which José Sarney assumed the presidency accounted for one of the main reasons for their weakness when he assumed the government. Housed in the historic moment of the decline of the military regime, the president-elect in opposition plate reaped the hostility of the streets and the indifference of the political establishmet. Knowing he could not count on the support of the political class nor the Brazilian society, Sarney tried to make the economic measures of broad popular impact his primary vehicle for legitimacy. After collapsing the Cruzado Plan, the president tried to make the negotiation of external debt his main political banner. He has sought, through the boastful tone in which he involved it, raise the internal support they so desperately needed.

KEYWORDS: Foreign debt; Moratorium; Jose Sarney; Legitimacy.

JEL Classification: F34.

\footnotetext{
" Respectivamente, Professor Adjunto e Professor Titular do Departamento de Economia e Relações Internacionais da Faculdade de Ciências Econômicas e do Programa de Pós-Graduação em Economia da Universidade Federal do Rio Grande do Sul (PPGE-UFRGS). E-mails: ivansalomao@gmail.com; pedro.fonseca@ufrgs.br. Submetido: 5/Janeiro/2015; Aprovado: 4/Setembro/2015.
} 


\section{INTRODUÇÃO}

A sequência de fatos históricos que levou José Sarney à Presidência da República responde por parcela significativa da crise de legitimidade que açoitou os cinco anos de seu mandato. As inúmeras aspirações políticas, reprimidas havia duas décadas pelo regime autoritário, terminaram por estreitar ainda mais o já tênue equilíbrio de forças sobre o qual o presidente governou o país. Desamparado pelas lideranças políticas, Sarney procurou nas ruas o apoio imprescindível a um governante carente de legitimidade.

Egresso da mais antiga e conservadora linhagem de políticos nordestinos, a figura de Sarney contrastava diretamente com os propósitos que haviam derrotado Paulo Maluf no colégio eleitoral. Ávida por mudanças, a sociedade brasileira negou apoio àquele que havia trabalhado explicitamente para derrotar a emenda das eleições diretas. A rejeição popular contribuiu para que o establishment nacional se arredasse ainda mais do já contestado presidente, lançando-o em um verdadeiro vácuo político.

A adoção de medidas econômicas de repercussão popular foi, portanto, a maneira pela qual o presidente tratou de conferir popularidade ao seu governo. A primeira e mais importante delas foi o lançamento do Plano Cruzado, em fevereiro de 1986. Exitoso em seu objetivo político, o sucesso inicial do plano heterodoxo de estabilização elevou Sarney à efêmera condição de estadista durante oito meses, período em que atingiu um dos mais elevados níveis de aprovação já auferidos entre os presidentes brasileiros.

Após o naufrágio do plano fugaz, o presidente encontrou nos entraves impostos pelos credores da dívida externa sua nova causa interna. Com efeito, o grau de deterioração das contas do balanço de pagamentos a que se chegou no início dos anos 1980 apresentava-se como um dos mais graves na história republicana brasileira. A política econômica durante os últimos anos do regime militar limitara-se a gerir, da maneira menos onerosa possível, os reveses impostos pela crise internacional.

A lógica de arcar com custos tão elevados quanto os decorrentes de uma moratória externa não carecia, portanto, de um acurado cálculo político. A esperada retaliação externa não influenciaria a decisão diante da sua necessidade de galgar o apoio dos políticos e da população. É neste sentido que se justifica a racionalidade política subjacente a medidas heterodoxas de ampla ressonância junto à opinião pública.

Assim sendo, este artigo tem o objetivo de problematizar a motivação política subjacente à decretação da moratória da dívida externa em 20 de fevereiro de 1987. Para tanto, dividiu-se o artigo em cinco partes, além desta breve introdução. $\mathrm{Na}$ segunda seção, discorre-se acerca da mudança qualitativa na negociação quando da gestão de Dilson Funaro no Ministério da Fazenda. A seguir, expõem-se as condições em que a moratória foi declarada. $\mathrm{Na}$ quarta seção, são apresentadas as repercussões decorrentes do anúncio da medida. Na próxima seção, explica-se por 
que se entende que a moratória esteve envolta a um cálculo político, seguida, por fim, pelas considerações finais.

\section{A ADMINISTRAÇÃO DA CRISE SOB DILSON FUNARO (08/1985-04/1987): A GUINADA SOBERANA}

Quando do segundo choque do petróleo, em 1979, a opção que se lhe fizera disponível ao governo brasileiro seis anos antes já não mais existia. À equipe econômica do presidente Figueiredo coube apenas e tão somente a pouco lisonjeira tarefa de administrar o pagamento dos débitos com os credores internacionais. $\mathrm{O}$ fechamento dos canais de rolagem da dívida após o calote mexicano, em 1982, impôs a necessidade de se adotar um ajuste recessivo de claro cunho ortodoxo, cujas consequências deletérias atuaram no sentido de deslegitimar ainda mais o regime militar.

Os descaminhos por que passou a negociação do governo brasileiro com os diversos interessados na questão (Tesouro norte-americano, o staff do FMI, além, é claro, dos representantes dos próprios credores) selaram o insucesso da tentativa de se atenuar os efeitos da crise. O excessivo rigor imposto pelos credores, aliado à reiterada aptidão por parte do país de descumprir os termos dos acordos pontuais, inviabilizaram qualquer acordo definitivo durante todo o mandato de Figueiredo (1979-1985).

O processo de renegociação com os credores externos sofreu acentuada inflexão com a nomeação de Dilson Funaro para o Ministério da Fazenda, em agosto de 1985. A recusa peremptória do novo ministro em submeter a economia brasileira ao monitoramento formal do FMI marcou todo o período em que este industrial paulista esteve à testa da delegação responsável pela gestão da dívida externa. A negação à tutela do Fundo não se justificava apenas pela rejeição ao ajuste recessivo sugerido por este órgão, mas também pela restrição de submeter o país a eventuais julgamentos na jurisdição da corte de Nova York (Bacha, 1987).

Duas semanas após assumir o cargo, Funaro foi ao encontro das autoridades econômicas dos Estados Unidos para anunciar as novas pretensões do governo brasileiro relacionadas à questão da dívida. Neste primeiro contato que manteve com o secretário do Tesouro norte-americano, James Baker, com o presidente do Fed, Paul Volcker, e com o diretor-gerente do Fundo, Jacques de Larosière, o ministro expôs as três condições das quais, doravante, o Brasil não abdicaria para renegociar sua dívida: a necessidade de um programa de ajuste de médio e longo prazos; uma programação que permitisse a continuidade do crescimento econômico; e a aplicação de uma terapêutica adequada à realidade histórica e social do país (Sampaio Júnior e Affonso, 1986).

Se a nova posição brasileira já havia sido eufemisticamente revelada no encontro de Washington, foi na reunião anual do FMI e do Banco Mundial, realizada no mês subsequente, em Seul, que o ministro Funaro expôs publicamente sua disposição de elevar as negociações a outro patamar qualitativo. A subserviência que o 
grupo de credores encontrou nos negociadores brasileiros até então cederia lugar a uma altivez não vista na diplomacia nacional desde o governo Geisel.

Reservou-se à primeira atividade oficial na capital sul-coreana a reunião inaugural entre a nova equipe econômica e o comitê de assessoramento ${ }^{1}$. O primeiro a se pronunciar foi já conhecido presidente do comitê, William Rhodes. Com o dedo em riste, disparou a um jovem assessor de Funaro: "Você com certeza haverá de se lembrar do que aconteceu com o seu país em 1983. Então eu pergunto: vai querer que tudo aquilo aconteça de novo? Será que vocês não vão aprender nunca?”. O tom de ameaça permeou todo o encontro no qual os seis burocratas brasileiros foram sucessivamente intimidados pelos mais de trinta representantes dos bancos comerciais. Ou se cedia ao arrocho proposto por Larosière ou seriam imediatamente suspensas as linhas de crédito a curto prazo no valor de US\$15 bilhões.

Não coube apenas ao grupo de "assessores" exercer pressão sobre a delegação brasileira no sentido de incitá-la à assinatura de um acordo formal com o FMI. Embora em outro diapasão, os três personagens com quem o ministro Funaro havia se encontrado no mês anterior voltaram a recomendar o ajuste avalizado pelo Fundo como única forma de destravar a negociação junto aos bancos credores. A rigidez com que se postou o ministro brasileiro, contudo, serviu para atenuar não apenas as investidas de seus interlocutores, como também para amainar a soberba com que estes costumavam a se dirigir às autoridades brasileiras.

O encontro anual das duas entidades multilaterais de 1985 proporcionou ainda dois episódios relevantes para o andamento da renegociação da dívida externa brasileira. O primeiro e mais inusitado foi o aparecimento do interlocutor até então incógnito do ministro Funaro. Enviado por Paul Volcker com o intuito de convencer o representante brasileiro a sucumbir ao programa do FMI, este funcionário do US Treasury viria posteriormente a influenciar de maneira decisiva as medidas adotadas pelo Ministério da Fazenda².

O segundo evento de impacto direto sobre as negociações da dívida externa foi o lançamento do chamado "Plano Baker". Ainda que suas cláusulas nunca tenham sido transportadas dos documentos oficiais para a realidade - em grande parte devido ao descumprimento das medidas a que se dispuseram a adotar os

\footnotetext{
${ }^{1}$ Compunham o comitê de assessoramento representantes de 14 bancos estrangeiros, sendo sete norte-americanos e mais um integrante de cada instituição dos seguintes países: Canadá, Japão, Inglaterra, França, Alemanha, Suíça e Arábia Saudita. Constituído, ao menos em teoria, para "assessorar" os negociadores brasileiros, este grupo teve todas as suas despesas operacionais pagas pelo governo brasileiro durante o tempo em que se manteve estabelecido (Nepomuceno, 1990).

${ }^{2} \mathrm{O}$ funcionário norte-americano solicitou uma audiência com o chefe da delegação brasileira em algum local ao ar livre, fora do hotel em que se hospedavam. Durante as duas horas em que tentou persuadir seu interlocutor da necessidade de se fechar um acordo com o Fundo, o "pombo-correio" conquistou a confiança de Dilson Funaro e, a partir daquele encontro insólito, passou a assessorar o ministro brasileiro fornecendo informações úteis para a negociação com os bancos credores ao longo de 1986 (Nepomuceno, 1990).
} 
bancos privados -, a sensível mudança no discurso do governo norte-americano em relação a algumas das demandas dos países devedores merece destaque.

A proposta inicial previa uma linha de financiamento de US\$ 29 bilhões ao longo de três anos, sendo US\$ 20 bilhões a serem obtidos junto aos bancos comerciais e o restante, ao Banco Mundial. Além do valor expressivo do crédito anunciado, acalentavam os anseios do ministro Funaro os depoimentos públicos do secretário do Tesouro norte-americano agora condizentes com a realidade latino-americana: os países devedores não mais poderiam aceitar condições de pagamento de suas dívidas que inviabilizassem o crescimento econômico. Ao entusiasmo inicial seguiu-se, porém, uma série de declarações desencontradas por parte das autoridades estadunidenses no que tocava à necessidade de submissão formal à tutela do Fundo para se obter acesso às condições do plano. Após meses de discordância, o plano caiu no vazio sem ter atingido seus objetivos iniciais ${ }^{3}$.

Ainda antes que o ano de 1985 terminasse, dois outros acontecimentos de impacto relevante sobre as contas externas brasileiras vieram a abalar a instável conjuntura em que seria lançado o Plano Cruzado. Os efeitos deletérios da severa seca que se arrastava havia meses sobre a safra agrícola da região Centro-Sul contribuíram não apenas para a explosão dos preços internos, mas principalmente para a diminuição do quantum exportado, atribulando ainda mais o resultado do balanço de pagamento em transações correntes (Souza, 1986).

Por fim, no último mês do ano, o presidente do Banco Central, Fernão Bracher, apresentou nova proposta ao comitê de assessoramento cujo principal elemento consistia na manutenção dos níveis correntes dos créditos comerciais e depósitos interbancários. Após meses de intensa negociação, chegou-se a um acordo provisório em março de 1986, o qual, embora modesto em termos de redução na transferência de recursos ao exterior, não deixou de ser celebrado pelo precedente aberto de se refinanciar uma parcela do principal sem um acordo formal com o FMI (Presser, 1986).

No início do ano seguinte, o ministro Dilson Funaro voltou aos Estados Unidos com o objetivo de persuadir o diretor-gerente do FMI a publicar uma nota elogiosa em relação ao andamento das contas externas brasileiras ${ }^{4}$. Após exaustivas reuniões, a maior resistência continuava a partir do presidente do Fed, para quem não restava outra opção a não ser o fechamento de um acordo formal com o Fundo sob o risco de inviabilizar o prosseguimento das negociações junto aos bancos credores. De posse da carta redigida por Larosière e diante da postura irremovível

\footnotetext{
${ }^{3}$ Para uma análise pormenorizada das propostas contidas no Plano Baker, ver, por exemplo, Baer, Macarini e Andrade (1986) e Presser (1986).

${ }^{4}$ A precariedade das condições de que dispunham os negociadores brasileiros é assim descrita pelo exMinistro do Planejamento, João Sayad: "Precisávamos ter firmas de advogados pra nos assessorar e profissionais brasileiros negociando a dívida externa full-time lá fora. O ministro da Fazenda e o presidente do Banco Central pegam um avião à noite, chegam lá cansados, não falam inglês direito, $\mathrm{e}$ têm que negociar com pessoas que estão na sua própria casa, dedicadas exclusivamente a isso, que conhecem todas as complexidades do mercado financeiro americano" (apud Solnik, 1988, p. 113).
} 
de Paul Volcker, Funaro acenou, pela primeira vez, com a possibilidade de suspender o pagamento da dívida, afirmando que já estava redigido o telex que comunicaria a suspensão dos pagamentos.

E foi neste ambiente de crescente beligerância na relação com os credores que veio a público, em 28 de fevereiro de 1986, o primeiro plano de combate à inflação da Nova República. Além dos efeitos imediatos sobre a balança comercial, o Cruzado influenciou de maneira determinante os rumos das negociações com os bancos internacionais. Ainda que efêmera, a popularidade que o plano conferiu ao governo serviu para munir-lhe do apoio interno decisivo na tentativa de buscar, ao longo daquele ano, uma solução favorável para o problema da dívida externa brasileira.

\section{A RUPTURA}

$\mathrm{Na}$ ausência de perspectivas de que seriam retomados os fluxos voluntários de empréstimos e/ou de uma redução expressiva das taxas de juros internacionais que impactasse significativamente a balança de serviços brasileira, a manutenção das condições em que o governo vinha honrando seus compromissos externos tendia, portanto, a perpetuar uma maciça transferência líquida de recursos reais aos países credores.

$\mathrm{Na}$ versão do assessor para assuntos da dívida externa do Ministério da Fazenda, Paulo Nogueira Batista Júnior, a moratória encarregou-se de dois objetivos econômicos. Ancorado em análises técnicas, pretendia-se, em um primeiro momento, estancar a perda das reservas cambiais do Banco Central. Além disso, o governo almejava alçar as negociações com os credores externos a outro patamar. Nas palavras do autor, a principal função da ruptura foi "sinalizar a determinação do governo brasileiro de modificar a natureza do processo de negociação e obter, através de uma negociação qualitativamente diferente, uma solução duradoura para o problema da dívida" (Batista Júnior, 1988, p. 30). A solução da crise dependeria, antes de tudo, de uma mudança da postura do governo brasileiro nas relações com os bancos credores.

As qualificações da suspensão, porém, é que garantiriam o sucesso deste segundo propósito. Era preciso demonstrar intenção inequívoca de se alterar o padrão da negociação. Unilateral, não se fariam consultas prévias. Soberana, não se pediria licença nem desculpas. E por tempo indeterminado, até que novas condições de pagamento se mostrassem interessantes o suficiente para se revogar a decisão. A moratória, portanto, tinha finalidades precisas e limitadas. Não se tratava de um fim em si mesmo com o simples objetivo de trazer dano aos bancos estrangeiros.

A proposta do governo brasileiro consistia em combinar a capitalização dos juros não pagos com a redução drástica do spread incidente sobre o estoque da dívida a partir de um refinanciamento automático de cinco anos. Além disso, propuseram-se medidas de proteção à vulnerabilidade intrínseca das taxas de juros pós-fixadas, como a transformação de parte da dívida flutuante a taxas fixas e a 
adoção de cláusulas de contingência ("teto") em caso de aumento inesperado das mesmas.

A suspensão dos pagamentos atingiu apenas os juros referentes à dívida de médio e longo prazo de credores bancários, alcançando aproximadamente o montante de US\$ 69 bilhões, dois terços do total da dívida externa brasileira (Batista Júnior, 1988). Assim, estavam excluídos da medida os juros referentes à dívida bancária de curto prazo - a fim de diminuir os riscos de uma redução abrupta das linhas de créditos essenciais ao funcionamento do comércio exterior - e de credores não bancários, como organismos multilaterais e agências governamentais. Dessa forma, o governo brasileiro, de imediato, deixava de transferir ao exterior cerca de US\$ 500 milhões por mês. Este caráter seletivo serviu para desarmar eventuais reações externas e reforçar as possibilidades de sucesso da iniciativa brasileira ${ }^{5}$.

Ainda assim, o governo havia tomado medidas de precaução antes de anunciar a medida. Em relação às reservas internacionais, tratou-se de retirá-las do alcance dos credores. O Banco Central mantinha cerca de metade de seu caixa sob a forma de depósitos em bancos comerciais estrangeiros, sujeitos, portanto, a confisco. A fim de minimizar o risco, estes haveres foram transformados em depósitos no Banco para Compensações Internacionais $(B I S)$ e em títulos governamentais, não sujeitos a embargo. Aos credores restariam apenas a opção acionar judicialmente $o$ governo ou os bancos brasileiros que operassem no exterior. Ainda assim, segundo Kaletsky (1988), as penalidades legais que coibiam a inadimplência eram mínimas se comparadas às vantagens financeiras da moratória.

Problemas na condução do processo, entretanto, turvaram esse horizonte promissor. O primeiro deles foi o atraso com que a moratória foi anunciada. Devido à incerteza em relação à sustentação política da medida, a postergação demasiada resultou em perda crucial de reservas, tornando a posição do governo mais vulnerável $^{6}$. Além disso, o momento em que foi decretada também atuou contra a posição brasileira, pois permitiu a ilação de que se tratava de um gesto típico de um país "quebrado", ao qual não restava alternativa senão a inadimplência. Somaram-se a estes reveses boatos de que subjazia a decisão do Ministério da Fazenda a intenção de se autarquizar ainda mais a já fechada economia brasileira.

A decisão do presidente Sarney de impedir que a moratória viesse acompanhada simultaneamente de medidas internas essenciais - como um novo e temporário

\footnotetext{
${ }^{5}$ Concluiu-se tal estratégia em 21/01/1987, quando do acordo fechado com o Clube de Paris. Ainda que modesto e insatisfatório, uma vez que o Brasil havia se comprometido a pagar em dia as suas dívidas, o êxito da negociação com o grupo de países credores prestou-se ao interesse do governo brasileiro de isolar os bancos comerciais e reduzir as tensões com outros credores (Meyer, 1992).

${ }^{6} \mathrm{O}$ próprio ministro do Planejamento na ocasião, João Sayad, admite o momento tardio em que a medida foi tomada: "Eu acho que a moratória é um instrumento de negociação. Hoje eu vejo com clareza que no dia 28 de fevereiro de 1986, quando a gente tinha 8 bilhões de dólares de reservas, naquele momento a gente deveria ter suspendido os pagamentos - com um plano definido e com dinheiro em caixa. Aí os bancos iriam negociar. Mais tarde, tinha que ser feito um braço de ferro com os banqueiros" (apud Solnik, 1988, p. 110).
} 
congelamento de preços a fim de garantir estabilidade econômica e política - pesou, esta sim, decisivamente para o insucesso da empreitada. Esta opção poderia não lhe parecer absurda do ponto de vista econômico, mas em seu cálculo político, porém, não havia oportunidade para mais um novo choque que tanto traumatizara a população em um espaço de tempo tão reduzido (Batista Júnior, 1988).

\section{AS REPERCUSSÕES IMEDIATAS}

Ao contrário do que previam aqueles que se postavam contra a suspensão dos pagamentos, as repercussões iniciais estiveram acima do esperado pela própria equipe econômica do governo. A despeito do peso da dívida brasileira no balanço de todas as principais instituições financeiras internacionais, a deflagração de uma guerra econômica contra o Brasil resultaria em um ambiente desastroso para os bancos, para as empresas multinacionais e, principalmente, para os interesses da política externa dos Estados Unidos (Kaletsky, 1988).

As possibilidades de represália eram, de fato, muito aquém das aventadas, uma vez que a retaliação comercial seria contraproducente e a interrupção do financiamento via fontes oficiais atuaria contra as exportações dos produtos manufaturados dos próprios países desenvolvidos. O resultado da balança comercial mostrou-se especialmente satisfatório. O Brasil atingiu, no último mês do ano, um saldo de US\$ 1,1 bilhão, rechaçando o principal argumento dos catastrofistas-por-dever-do-ofício.

Seguiu-se ao anúncio da moratória uma já esperada redução das linhas e dos prazos de crédito voluntário uma elevação dos spreads. Em casos específicos, a retaliação dos bancos estrangeiros limitou-se ao atraso na compensação de operações interbancárias de bancos brasileiros (Lago, 1988). O impacto, porém, foi satisfatoriamente amortecido pela bem-sucedida capitalização unilateral dos juros, a qual, em pouco tempo, lograria recompor as reservas internacionais a um nível menos vulnerável caso a postura soberana não houvesse sido abandonada pelo presidente Sarney.

Em suma, a despeito da indignação inicial, os bancos credores mostraram-se resignados. Passariam a atuar de modo mais ostensivo, é verdade. Mas encontravam-se, pela primeira vez desde o início das negociações, na defensiva. As previsões de que os governos dos países cujos bancos foram atingidos pela medida recorreriam à violência e de que bens brasileiros no exterior seriam confiscados não se realizaram.

Do ponto de vista político, contudo, não se pôde contabilizar o mesmo êxito. A repercussão negativa junto a vários setores da sociedade, e em especial, à parcela relevante do seu próprio partido ${ }^{7}$, precipitou o arrependimento imediato do presidente da República. Acusaram-no de querer desviar a atenção dos problemas

\footnotetext{
${ }^{7}$ Os governadores dos três principais estados brasileiros - Orestes Quércia (SP), Moreira Franco (RJ) e Newton Cardoso (MG), todos pertencentes ao PMDB - já haviam publicamente pedido a saída do
} 


Tabela 1: Exportações, Importações e Saldo da Balança Comercial
\begin{tabular}{cccc} 
Brasil, 02/1987-12/1987 (em milhões de US $\$$ ) \\
\hline Mês & Exportações & Importações & $\begin{array}{r}\text { Balança } \\
\text { Comercial }\end{array}$ \\
\hline $02 / 1987$ & $1.452,00$ & $1.131,70$ & 320,30 \\
$03 / 1987$ & $1.436,00$ & $1.133,90$ & 302,10 \\
$04 / 1987$ & $1.673,00$ & $1.170,90$ & 502,10 \\
$05 / 1987$ & $2.187,00$ & $1.226,90$ & 960,10 \\
$06 / 1987$ & $2.643,00$ & $1.212,90$ & $1.430,10$ \\
$07 / 1987$ & $2.923,00$ & $1.466,00$ & $1.457,00$ \\
$08 / 1987$ & $2.755,00$ & $1.326,60$ & $1.428,40$ \\
$09 / 1987$ & $2.692,00$ & $1.194,90$ & $1.497,10$ \\
$10 / 1987$ & $2.505,00$ & $1.312,20$ & $1.192,80$ \\
$11 / 1987$ & $2.247,00$ & $1.245,50$ & $1.001,50$ \\
$12 / 1987$ & $2.447,00$ & $1.330,00$ & $1.117,00$ \\
\hline
\end{tabular}

Fonte: Ipeadata.

internos com medidas extravagantes. Hostilizado pela opinião pública e submetido a pressões externas, Sarney decidiu que tal estratégia de negociação traçada pela equipe do Ministério da Fazenda não mais seria levada adiante. Sua insatisfação com os pífios dividendos políticos arrebanhados pela moratória e a falta de sustentação política foram os principais motivos que derrubaram o ministro Funaro e sua equipe dois meses após o seu anúncio.

A população em geral não identificou benefício algum na medida, pois nela não enxergou uma mudança concreta que interferisse diretamente no seu padrão de vida. Caso tivesse vindo acompanhada do novo choque interno proposto pelo Ministério da Fazenda ${ }^{8}$, a reação da sociedade - novamente em litígio com o governo após a trégua trazida pelo Cruzado - poderia ter sido diferente. A moratória isolada, em um contexto de dificuldades, soou mais como um golpe publicitário de um presidente desesperado que governava um país à beira da falência.

O fracasso da tentativa heterodoxa de renegociação da dívida externa, conforme a versão veiculada pela grande imprensa, foi creditado à figura de José Sarney. Mas a ineficiência da articulação política que sustentaria a medida, condição sine qua non para o êxito de um projeto de tal magnitude, pôde ser delegada também ao corpo burocrático e à equipe de comunicação do Ministério da Fazenda - o único setor do governo verdadeiramente comprometido com a iniciativa -, os quais

ministro Dilson Funaro enquanto este se encontrava no exterior em negociação com os credores externos.

\footnotetext{
${ }^{8}$ No final de janeiro de 1987, o Ministério da Fazenda enviou um documento ao presidente José Sarney ("Proposta para uma Ação de Governo") no qual reforçou a necessidade de se decretar a moratória juntamente com a adoção de um novo choque de estabilização interno, alarme ignorado pelo presidente da República.
} 
não souberam transmitir a ideia de maneira adequada aos atores sociais que poderiam sustentar e elucidar a medida perante a população.

\section{A MORATÓRIA COMO INSTRUMENTO DE LEGITIMAÇÃO POLÍTICA}

Recorrendo-se a uma opção metodológica que enfatiza a interação entre variáveis econômicas e políticas, aponta-se neste artigo para a conveniência da utilização de medidas econômicas como forma de conferir legitimidade política a um governo fraco. Neste sentido, o exercício teórico de delegar a motivos puramente técnicos a suspensão do pagamento dos juros da dívida externa, como reiteradamente o fez o ex-presidente José Sarney em seus pronunciamentos ${ }^{9}$, não encontra respaldo na análise dos dados, convindo apenas para eximir seu governo de responsabilidades ante à suposta inevitabilidade dos fatos. $\mathrm{O}$ principal argumento a sustentar a referida hipótese reside, portanto, na análise econômica da conjuntura, a qual revela a clara existência de, pelo menos, duas medidas alternativas à moratória.

Para embasar esta argumentação, deve-se, em primeiro lugar, analisar a situação das reservas internacionais no início de 1987 com o intuito de desmistificar a suposta imperiosidade econômica da decisão. $\mathrm{O}$ valor absoluto líquido das reservas sob posse da autoridade monetária sinaliza, ainda que de maneira imperfeita, a posição de defesa cambial ostentada pelo governo de um ponto de vista estático. Assim sendo, se comparado o valor das reservas brasileiras ao final do segundo mês do ano de 1987 aos que vinham sendo computados desde dezembro de 1982, verifica-se que não foi a escassez de moedas conversíveis propriamente dita que determinou a ruptura ${ }^{10}$.

Ainda no que toca à questão cambial, do ponto de vista da atividade econômica, a capacidade de importação de um país está diretamente atrelada ao nível destas reservas ${ }^{11}$, uma vez que o comércio internacional pressupõe negociações realizadas em divisas estrangeiras, em especial, o dólar norte-americano. Desta forma, a relação reservas cambiais/importações torna-se variável fundamental para a administração das contas do balanço de pagamentos. Considerando uma série histórica mensal de janeiro de 1983 a fevereiro de 1987, pode-se observar que a razão registrada em fevereiro de 1987 entre as reservas disponíveis no último dia de cada mês (RI) sobre

\footnotetext{
9 Para uma análise detalhada dos pronunciamentos do presidente José Sarney ver Pinto (1989) e Salomão (2010).

${ }^{10}$ Emprega-se nesta análise o valor das reservas no conceito de caixa (depósitos livres no sistema bancário internacional, além do disponível e do ouro). Se se utilizasse o valor correspondente à liquidez internacional (haveres prontos, de curto, médio e longo prazos, em moedas conversíveis), este argumento ganharia maior validade ainda, uma vez que neste segundo conceito registram-se valores consideravelmente superiores aos do primeiro.

${ }^{11}$ De acordo com Bocchi (2000), considerava-se seguro, à época, um nível de reservas cambiais aquele capaz de garantir pelo menos três meses de importações. Em fevereiro de 1987, o Banco Central - no caso extremo de paralisia dos fluxos voluntários de recursos - poderia garantir aos importadores brasileiros, ainda assim, um período superior a 90 dias de aquisição de bens e serviços do exterior.
} 
Tabela 2 - Ranking das Reservas Internacionais

Brasil, 12/1982-02/1987 (em milhões de US\$)

\begin{tabular}{lcc}
\hline Mês & RI & Ranking \\
\hline $10 / 1983$ & $-2.201,00$ & 1 \\
$08 / 1983$ & $-2.182,00$ & 2 \\
$09 / 1983$ & $-1.972,00$ & 3 \\
$11 / 1983$ & $-1.894,00$ & 4 \\
$12 / 1983$ & $-1.555,00$ & 5 \\
$07 / 1983$ & $-1.246,00$ & 6 \\
$06 / 1983$ & $-1.014,00$ & 7 \\
$02 / 1983$ & $-912,00$ & 8 \\
$05 / 1983$ & $-872,00$ & 9 \\
$04 / 1983$ & $-769,00$ & 10 \\
$03 / 1983$ & $-725,00$ & 11 \\
$01 / 1983$ & 295,00 & 12 \\
$01 / 1984$ & 538,00 & 13 \\
$12 / 1982$ & 938,00 & 14 \\
$02 / 1984$ & $1.116,00$ & 15 \\
$03 / 1984$ & $1.430,00$ & 16 \\
$04 / 1984$ & $2.444,00$ & 17 \\
$02 / 1987$ & $3.331,00$ & 18 \\
\hline & Fonte: Ipeadata. & \\
& &
\end{tabular}

as importações contabilizadas no mês imediatamente anterior $(\mathrm{M}-1)^{12}$ não exigia, por si só, a suspensão imediata do pagamento do serviço da dívida externa.

Conforme pode ser analisado na Tabela 3, a relação RI/M-1 mostrou-se novamente inferior à do momento em que se declarou a moratória em nada menos que em 17 outras oportunidades. Durante todo o dramático ano de 1983 e em quatro meses de 1982, a fração entre estas duas variáveis atingiu valores ainda menores, o que demonstrava a existência de outros caminhos que não somente a inadimplência.

Os dados acima apresentados evidenciam a situação administrável das contas externas no início de 1987, a qual, ainda assim, permitia espaço para que se propusessem alternativas ortodoxas de combate à crise. A primeira delas consistia em adotar medidas internas contracionistas voltadas a restabelecer o equilíbrio das contas externas. Com o aval dos credores privados e garantidos os fluxos dos "empréstimos-ponte" ${ }^{13}$, o país poderia reescalonar o principal da dívida e financiar parcela dos juros a fim de se evitar atrasos no pagamento dos débitos enquanto se dispusesse de reservas.

\footnotetext{
${ }^{12}$ A defasagem dos dados relativos à importação faz-se oportuna uma vez que, na gestão cotidiana da política econômica, não se podia prever o montante importado do mês corrente antes que o mesmo findasse. Se fossem considerados os valores das importações correntes, a fração referente a fevereiro de 1987 encontrar-se-ia na $20^{a}$ posição deste ranking.

${ }^{13}$ Este mecanismo de emergência consistia em contratar novos empréstimos, a custos significativamente mais altos, para honrar pontualmente os juros devidos por empréstimos passados (Bacha, 1983).
} 


\section{Tabela 3 - Ranking da razão Reservas Internacionais/Exportações do mês anterior Brasil (01/1983-02/1987)}

\begin{tabular}{ccc}
\hline Mês & RI/M-1 & Ranking \\
\hline $08 / 1983$ & $-1,9$ & 1 \\
$10 / 1983$ & $-1,7$ & 2 \\
$11 / 1983$ & $-1,5$ & 3 \\
$09 / 1983$ & $-1,4$ & 4 \\
$12 / 1983$ & $-1,2$ & 5 \\
$07 / 1983$ & $-1,1$ & 6 \\
$06 / 1983$ & $-0,8$ & 7 \\
$05 / 1983$ & $-0,7$ & 8 \\
$02 / 1983$ & $-0,6$ & 9 \\
$04 / 1983$ & $-0,6$ & 10 \\
$03 / 1983$ & $-0,6$ & 11 \\
$01 / 1983$ & 0,2 & 12 \\
$01 / 1984$ & 0,4 & 13 \\
$02 / 1984$ & 1,0 & 14 \\
$03 / 1984$ & 1,4 & 15 \\
$04 / 1984$ & 2,3 & 16 \\
$01 / 1987$ & 2,4 & 17 \\
$02 / 1987$ & 2,6 & 18 \\
\hline Fonte: elaboração própria, a partir dos dados & disponibilizados pelo lpeadata. \\
\hline
\end{tabular}

Caso se optasse por esse caminho, fazia-se coerente a possibilidade de decretar uma maxidesvalorização nominal do cruzado a fim de estimular as exportações e inibir a aquisição de bens e serviços no exterior, deslocando a demanda através da alteração dos preços relativos. Esta opção esbarrava, contudo, em seus efeitos inflacionários no momento em que o já desmoralizado governo não contava com cacife político suficiente para justificar novo aumento deliberado de preços.

Em segundo lugar, não era negada ao governo brasileiro a alternativa de recorrer formalmente ao programa de ajustamento proposto pelo FMI desde 1983, a qual condizia, cabe ressaltar, com o histórico de um político de tradição conservadora e representante das causas mantenedoras da ordem, como sempre fora José Sarney. Havia neste sentido não apenas a pressão da comunidade internacional, mas também a sugestão da maior parte dos acadêmicos brasileiros e de membros da própria equipe do governo, o que demonstra que o default não se tratava de um fim inescapável. A inevitável repercussão negativa que teria acompanhado esta opção, porém, acabou por inviabilizá-la desde o primeiro momento.

Faz-se mister ressaltar que essa postura acomodatícia era defendida pela maioria dos economistas que à época analisava a crise da dívida externa brasileira. Em artigo de caráter retrospectivo, Mário Henrique Simonsen assim definiu a medida adotada pelo governo brasileiro: "Em fevereiro [de 1987], com as reservas raspadas pelo carnaval do Cruzado, teríamos que atrasar alguns pagamentos externos, apenas. Ao invés de apelar para a técnica do empréstimo-ponte, ou para o 'devo, não 
nego, pagarei quando puder', apelou-se apenas para a bravata" (apud Batista Júnior, 1988, p. 25-26).

Nos meses que antecederam o anúncio da medida, travou-se uma verdadeira "guerra surda" entre os técnicos alocados no Ministério da Fazenda e os burocratas do Banco Central - com destaque para o presidente do banco, Fernão Bracher ${ }^{14}$, e para o embaixador brasileiro em Washington, Marcilio Marques Moreira -, os quais condenavam ferreamente a postura altiva adotada pelos negociadores brasileiros desde setembro de 1985. Para eles, os ônus da inadimplência superavam em muito os decorrentes da submissão ao monitoramento do FMI ${ }^{15}$. Esta divergência de prognóstico falseia ainda mais a versão de que não restava alternativa ao governo além da moratória. Desmente em definitivo esta hipótese a assunção, por parte do principal burocrata do Ministério da Fazenda encarregado da questão da dívida externa, de que não se tratou de uma decisão meramente econômica ${ }^{16}$ : "A posição defendida pelo ministro Dilson Funaro prevaleceu por motivos essencialmente políticos" (Batista Júnior, 1988, p. 41, grifo nosso).

Além destas duas alternativas de política econômica de que se dispunha naquele momento, outras três observações robustecem de modo ainda mais persua-

14 Crente de que os créditos voluntários seriam em breve restabelecidos, Fernão Bracher utilizava-se desta esperança para argumentar que, caso o governo decretasse a moratória, o país estaria "morrendo na praia". Esta fé rendeu-lhe, entre os assessores do Ministério da Fazenda, a alcunha de Fernão "Terra à Vista" Bracher (Nepomuceno, 1990). Ciente de que a sua posição seria preterida, Bracher demitiu-se da presidência do Banco Central em 11 de fevereiro, nove dias antes do anúncio da suspensão.

${ }^{15}$ Os analistas que se postavam contrários ao deafult não estavam despossuídos de argumentos técnicos para atuarem em favor do pagamento da dívida, sendo estes os pontos centrais dos que assim raciocinavam: (1) um país que contraiu dívida no exterior tem a obrigação moral de fazer o possível para cumprir seus compromissos financeiros; (2) a suspensão dos pagamentos inviabilizaria a tomada de novos empréstimos externos, afastando a possibilidade de reintegração do país ao mercado financeiro internacional; (3) a moratória desencadearia pesadas retaliações contra o Brasil, que anulariam os benefícios advindos da interrupção do pagamento de juros; e (4) a moratória jamais encontraria apoio interno suficiente dado o grau de articulação entre os interesses externos e os setores dominantes da sociedade brasileira (Batista Júnior, 1988).

16 Tradicionalmente o mainstream negligenciou as variáveis políticas e institucionais na análise econômica, as quais eram incluídas no recurso metodológico "coeteris paribus"; mesmo análises marxistas relegavam-nas a segundo plano, ao tratá-las, em uma leitura ortodoxa, como "superestrutura". Em período mais recente, e principalmente nas últimas duas décadas, vários autores têm procurado, de diferentes formas, incorporar tais variáveis em seus modelos. Apenas como menção, podem-se identificar quatro abordagens neste sentido: (a) a Nova Economia Institucional, em autores como North (1990, 1991, 1994, 2005), Coase (1988, 1993), Williamson (1985, 1993, 1996, 2000) e Nelson (1995, 2001), dentre outros; (b) trabalhos voltados a incorporar variáveis políticas em modelos macroeconômicos, mostrando a relação entre partidos, credibilidade, calendário eleitoral e orientação ideológica dos governos com inflação, emprego e crescimento, a exemplo de Alesina, Roubini e Cohen (1997) e Persson e Tabellini (1990, 1994a, 1994b, 1995); (c) trabalhos correlatos à teoria da escolha pública, como de Mueller (1989, 1997), Wittman (1989, 1995), Weingast, Shepsle e Johsen (1981), Drazen (2000), Weingast (2005); e (d) os modelos referentes a ciclo político, estes já de maior tradição, como nos trabalhos de Downs (1957), Nordhaus (1975), Lindbeck (1976), McRae (1977), McCallum (1978), Hibbs (1986, 1977), Alesina (1987), Rogoff e Sibert (1988) e Rogoff (1990). 
sivo a ideia de que a moratória não se tratou de um evento economicamente inevitável.

Em primeiro lugar, se a situação das reservas cambiais e da balança comercial exigia, de fato, alguma cautela, não se podia desconsiderar, ainda, que o cenário do comércio externo apresentado para o ano de 1987 era incomparavelmente mais otimista se comparado àquele que se avistara para 1983. A crise internacional já havia sido superada pela maioria dos países desenvolvidos dos quais o Brasil obtinha seus maiores saldos de exportação. A economia dos principais parceiros comerciais do país crescia havia mais de três anos seguidos ${ }^{17}$ : Argentina $(7,1 \% \mathrm{em}$ 1986 e 2,5\% em 1987); Estados Unidos (7,2\% em 1984, 4,1\% em 1985, 3,4\% em 1986 e 3,3\% em 1987); América (6,5\% em 1984, 4,0\% em 1985, 3,5\% em 1986 e $3,4 \%$ em 1987) e Europa Ocidental (4,1\% em 1984, $1,5 \%$ em 1985, 1,8\% em 1986, e 2,1\% em 1987).

Além disso, revela o caráter não imperioso da medida o fato de a decisão ter sido previamente acertada. Nepomuceno (1990, p. 176), em análise dos bastidores da negociação da dívida externa, revela que a moratória fora aventada pela primeira vez havia pelo menos seis meses, tendo ganhado ainda mais força após as reações negativas às medidas do Cruzado II. Indo além, em um lance que beirava a pura estratégia eleitoral, o presidente Sarney chegou a determinar a data em que seria declarado o default: 15/10/1986. O impasse nas negociações e o risco de abalar a frágil estrutura externa em que se apoiava o já condenado Plano Cruzado demoveram-no da ideia (Nepomuceno, 1990).

Por fim, reforça de maneira conclusiva a hipótese defendida neste artigo um elemento aparentemente menor não fosse a simbologia que o caracterizou. Do ponto de vista da racionalidade política, não se deve desconsiderar o veículo utilizado pelo presidente para anunciar a decisão: um discurso transmitido em rede nacional de rádio e televisão em horário nobre ${ }^{18}$. Sarney pretendia, assim, transformar a medida, supostamente técnica, em um evento cerimonioso. Pinto (1989, p. 73) ressalta a excepcionalidade deste tipo de ocasião ao destacar que o presidente da República "só faz um pronunciamento desta natureza quando tem uma mensagem especial a transmitir. É um momento simbólico - o governo, na pessoa de seu mais alto funcionário, se apresenta solenemente ao público".

Meses antes de a moratória ter sido chancelada por Sarney, Faoro (2008, p. 83) já atentava para esta possibilidade de o presidente utilizar-se da medida última para, através da grande mídia, granjear o respaldo da sociedade:

${ }^{17}$ Dados do United Nations Statistic Division: http://unstats.un.org/unsd/snaama/introduction.asp. Acesso em 09/11/2014.

${ }^{18}$ A despeito da beligerância dos pronunciamentos proferidos nos dois primeiros anos de seu governo, Sarney tratou de transmitir serenidade ao anunciar a interrupção da rolagem da dívida. No discurso transmitido em rede nacional de rádio e televisão, na noite do dia 20 de fevereiro de 1987, o presidente utilizou um tom brando, evitando a confrontação, a fim de minimizar eventuais represálias. Mas não foram apenas os credores internacionais que se sublevaram. A “quinta coluna” brasileira, conforme já destacado, atuou em peso para o fracasso da medida. 
Se esse acordo [da dívida externa] não se fechar, ele teria a hipótese de ir para a televisão e anunciar uma moratória - que também lhe daria popularidade, mas aí em período bem mais curto. Seria um outro momento de popularidade dele, mas aí com todas as incertezas e dificuldades que advêm de uma moratória.

Ainda que a medida não tenha atingido os objetivos esperados pelo presidente, cabe ressaltar pelo menos um dos fins políticos a que a moratória teria se prestado. Diante da disputa interna travada entre os diferentes órgãos do governo, a posição defendida pelo Ministério da Fazenda predominou por motivos essencialmente políticos. Batista Júnior (1988) ressalta à exaustão que a ameaça político-jurídica que rondava seu mandato de cinco anos incitou o presidente Sarney a granjear, mais do que nunca, toda o apoio popular que lhe fosse possível a fim de que não tivesse decepado um quinto de seu governo ${ }^{19}$.

Eis, portanto, os cálculos políticos da moratória.

Diante dos indícios de que não foram as imperiosidades técnicas que levaram o Brasil a suspender o pagamento dos juros de sua dívida externa, faz-se necessário recorrer a outros fatores para elucidar a intencionalidade subjacente à medida. Conforme argumenta Fonseca (2004, p. 591), "se é difícil encontrar uma racionalidade estritamente econômica para o comportamento do governo, o mesmo não ocorre quando se traz à baila variáveis de natureza política". E é neste sentindo que apontam as evidências arroladas neste trabalho: a despeito do embasamento teórico sobre o qual foi arquitetada, a moratória respondeu, primordialmente, a exigências de cunho político.

\section{CONSIDERAÇÕES FINAIS}

Ciente de que não contaria com o apoio das ruas, tampouco com a benemerência do Congresso Nacional, José Sarney tratou de fazer da negociação da dívida externa uma de suas principais bandeiras políticas, tendo pretendido, através do tom ufanista em que a envolveu, angariar o apoio interno de que tanto necessitava. A dissonância entre o aspecto político da questão ressaltado pelo governo desde 1985 e a suposta imperiosidade técnica em que teria se calcado a moratória - ar-

\footnotetext{
${ }^{19}$ Contra aqueles que o acusam de empunhar a moratória a fim de ter tido alongado seu mandato, o ex-presidente não se exime de contra-argumentar: "Este foi um dos maiores erros da mídia, no Brasil. Passaram ao público a ideia de que prorroguei meu mandato em um ano quando, na verdade, eu abdiquei de um ano. Meu mandato, firmado no termo de posse assinado pela mesa do Congresso, em função da lei então vigente, expirava em 1991, no mês de março. Era, portanto, um mandato de seis anos, como fora o do presidente anterior. Para pacificar o ambiente, já tumultuado pelo açodamento de alguns candidatos à minha sucessão, declarei que aceitava a fórmula de 'cinco anos'. Aí desencadeou-se a campanha pelos quatro anos. Eu cometi um erro, confesso. Devia ter ficado calado. Caso a Constituinte fixasse meu mandato em quatro anos, bastaria ir ao Supremo, que confirmaria os seis direito adquirido pelo diploma que me outorgaram” (apud Bastos, 2001, p. 33).
} 
gumento apresentado pelo presidente, vinte anos mais tarde, como sua única justificativa - revela o esperado bônus político que a ruptura não logrou atingir.

A adoção de medidas econômicas de ampla repercussão foi, portanto, o modo pelo qual o presidente instrumentalizou as tentativas de conferir popularidade ao seu governo. Bem-sucedido em seu objetivo político, o êxito inicial do Plano Cruzado conferiu ao governo a popularidade de que tanto necessitava o presidente deslegitimado em função de sua biografia política.

Diante da sucumbência daquele que temporariamente conferira algum respaldo popular ao seu governo, o presidente Sarney encontrou nas vicissitudes impostas pela dívida forânea sua nova causa. A convivência com um cenário externo adverso que lhe restringisse maiores aspirações não era situação alheia à economia brasileira. O grau de deterioração das contas do balanço de pagamentos a que se chegou no início da década de 1980, contudo, não havia encontrado paralelo até então na história republicana. A política econômica durante os últimos anos do governo Figueiredo limitou-se a administrar os reveses impostos pelo estrangulamento do balanço de pagamentos.

A negociação junto aos representantes dos bancos internacionais ganhou nova forma e conteúdo a partir do segundo semestre de 1985, quando tomou posse o novo ministro da Fazenda, Dilson Funaro. Disposta a elevar as condições da rolagem da dívida a outro patamar qualitativo, a nova delegação brasileira reuniu-se exaustivamente com os representantes das instituições credoras e do governo norte-americano a fim de se chegar a uma resolução que dispensasse a adesão formal ao monitoramento do Fundo Monetário Internacional. Diante da recusa peremptória do governo brasileiro em submeter-se a um programa de ajuste recessivo preconizado pelo FMI, a negociação manteve-se praticamente paralisada no decorrer de 1986.

Aproximava-se cada vez mais da opção pela ruptura à medida em que, a partir de setembro, passaram a se repetir mensalmente os resultados negativos das contas externas - em decorrência do já previsto e calculadamente postergado colapso do Plano Cruzado. O exaurimento das reservas cambiais era, de fato, preocupante, uma vez que, em menos de um ano, haviam sido reduzidas a menos da metade do valor em que se encontravam antes do lançamento do plano. $\mathrm{O}$ aval do presidente da República, entretanto, não esteve condicionado pela crescente dificuldade de se custear as importações em moeda estrangeira.

A lógica de arcar com custos tão elevados quanto os decorrentes desta ruptura internacional não carecia, portanto, de um preciso cálculo político. A esperada retaliação externa pouco influenciaria a decisão diante da desde sempre presente necessidade, por parte do presidente José Sarney, de galgar à adesão dos mais diversos setores da sociedade brasileira. É neste sentido que se justifica a racionalidade política das medidas heterodoxas de ampla repercussão junto à opinião pública. Ao apelo chauvinista da moratória não faltou embasamento técnico. $\mathrm{O}$ pretendido bônus político, entretanto, mostrou-se decisivo para persuadir um presidente da República com as credenciais supracitadas a patrocinar medida de tamanha envergadura. 


\section{REFERÊNCIAS BIBLIOGRÁFICAS}

ALESINA, A.; ROUBINI, N.; COHEN, G. (1997) Political Cycles and the Macroeconomics. Cambridge, MA: MIT Press.

BACHA, Edmar L.(1983) "IMF and the prospects for maladjustments um Brazil. In: John Williamson, org. Prospects for Adjustment in Argentina, Brazil and Mexico. Washington, Institute for International Economics.

BACHA, Edmar L.(1987) Do Acordo de Plaza a Moratória Técnica: Os Tortuosos Caminhos da Renegociação da Divida Externa Brasileira: 1983-87. Rio de Janeiro: PUCRJ.

BAER, Mônica (1989) “A dívida externa brasileira: estratégias de negociação e impactos internos (19831987)". In Luiz Carlos Bresser-Pereira, org. Dívida Externa. Crise e Soluções. São Paulo: Brasiliense.

BAER, Mônica; MACARINI, José Pedro; ANDRADE, Rogério P. de. (1986) “A performance em 1985 e o contexto favorável ao Plano Cruzado". In Ricardo Carneiro, org. Política Econômica da Nova República. Rio de Janeiro: Paz e Terra.

BASTOS, Evandro de O., coord. (2001) Sarney: O Outro Lado da História. Rio de Janeiro: Nova Fronteira.

BATISTA JÚNIOR, Paulo N. (1981) “ Participação brasileira no mercado financeiro internacional: custo e perfil da dívida externa brasileira”. Estudos Especiais IBRE, n. 2. Rio de Janeiro: FGV.

BATISTA JÚNIOR, Paulo N. (1983) Mito e Realidade da Dívida Externa Brasileira. Rio de Janeiro: Paz e terra.

BATISTA JÚNIOR, Paulo N. (1988) Da Crise Internacional à Moratória Brasileira. Rio de Janeiro: Paz e Terra.

BOCCHI, João Ildebrando (2000) "Restrições externas e desenvolvimento econômico no Brasil: o eterno retorno". Cadernos PUC, São Paulo, v. 9, p. 15-47, 2000.

BRANT, Celso (1986) Quem Tem Medo da Moratória? Rio de Janeiro: Riquel.

CARNEIRO, Dionísio D. (1992) "Crise e esperança”. In Marcelo de P. Abreu, org. A Ordem do Progresso. Cem Anos de Política Econômica Republicana. Rio de Janeiro: Campus.

CARNEIRO, Dionísio D.; MODIANO, Eduardo M. (1992) "Ajuste externo e desequilíbrio interno: 1980-1984”. In: Marcelo de P. Abreu, org., A Ordem do Progresso. Cem Anos de Política Econômica Republicana. Rio de Janeiro: Campus.

COASE, R H. (1988) The Firm, the Market and the Law. Chicago/London: The University Chicago Press.

COASE, R H. (1993) “ Nobel Lecture: The institutional structure of production”. In Oliver Williamson and Sidney G. Winter, The Nature of the Firm: Origins, Evolution, and Development. New York/ Oxford: Oxford University Press.

COUTINHO, Luciano G. (1983) Pontos mínimos para uma negociação externa soberana e realista. In João Manuel C. De Mello, Luiz Gonzaga de M. Belluzzo, orgs. FMI x Brasil. A Armadilha da Recessão. São Paulo: Gazeta Mercantil.

DOWS, A. (1957) An economic theory of political action in a democracy" Journal of Political Economy, vol. 65 , n. 2, p. 135-50.

DRAZEN, A. (2000) Political Economy in Macroeconomics. Princeton, N. J.: Princeton University Press,.

FAORO, Raymundo (2008). A Democracia Traída. Entrevistas. São Paulo: Globo.

FONSECA, Pedro Cezar D. (2004) "Legitimidade e credibilidade: Impasses da política econômica do Governo Goulart”. Estudos Econômicos, São Paulo, v. 34, n. 3, p. 587-622, Jul./Set..

FURTADO, Celso M. (1982) A Nova Dependência. Divida Externa e Monetarismo. Rio de Janeiro: Paz e Terra.

FURTADO, Celso M. (1989) ABC da Dívida Externa, Rio de Janeiro: Paz e Terra, 1989.

HIBBS, D. (1986) "Political parties and macroeconomic policies and outcomes in the United States". American Economic Review Papers and Proceedings, vol. 76, n. 2, p. 66-70.

HIBBS, D. (1977) "Political parties and macroeconomic policy". American Political Science Review, vol. 71, p. 1467-87. 
KALETSKY, Anatole (1988). Os Custos da Moratória. Rio de Janeiro: Paz e Terra.

LAGO, Luiz Aranha C. Do (1988) “A suspensão do pagamento dos juros da dívida externa”. In Paulo N. Batista Júnior, org. Novos Ensaios sobre o Setor Externo da Economia Brasileira. Rio de Janeiro: FGV-IBRE.

LINDBECK, A. (1976) "Stabilization policies with open economies and endogenous politicians". American Economic Review Papers and Proceedings, p. 1-19.

MALAN, Pedro S. (1983) “A questão externa”. In João Manuel C. Mello; Luiz Gonzaga de M. Belluzzo, orgs. Fmi x Brasil. A Armadilha da Recessão. São Paulo: Gazeta Mercantil.

McCALLUM, B. (1978) "Political business cycle: an empirical test". Southern Economic Journal, vol. 44, p. 504-15.

McRAE, C. D. (1977) “A political model in business cycle”. Journal of Political Economy, vol. 85, n. 2, p. 239-263.

MELLO, João Manuel C. de; BELLUZZO, Luiz Gonzaga de M., orgs. (1983) FMI x Brasil. A Armadilha da Recessão. Gazeta Mercantil.

MEYER, Arno (1992) As negociações da dívida externa brasileira no âmbito do Clube de Paris. In Luiz Gonzaga de M. Belluzzo e Paulo N. Batista Júnior, orgs. A Luta pela Sobrevivência da Moeda Nacional: Ensaios em Homenagem a Dilson Funaro. Rio de Janeiro: Paz e Terra.

MOURA, Alkimar R. (1990) "Rumo à entropia: a política econômica, de Geisel a Collor”. In Bolívar Lamounier et al.., org. De Geisel a Collor: O Balanço da Transição. São Paulo: Editora Sumaré.

MUELlER, D. C. (1989) Public Choice II. Cambridge: Cambridge University Press.

MUELleR, D. C. (1997) Perspectives on Public Choice: A Handbook. New York: Cambridge University Press.

MUNHOZ, Dércio G. (1983) "Negociação com os bancos credores: a urgência na redefinição de objetivos”. In João Manuel C. Mello; Luiz Gonzaga de M. Belluzzo, orgs. Fmi x Brasil. A Armadilha da Recessão. São Paulo: Gazeta Mercantil.

NELSON, Richard R. (1995) "Recent evolutionary theorizing about economic change". Journal of Economic Literature, vol. 33, p. 48-90.

NELSON, Richard; SAMPAT, Bhaven. Las instituciones como factor que regula el desempeño económico. Revista de economía institucional vol.3, n. 5, p. 17-51, 2001.

NEPOMUCENO, Eric. (1990) O Outro Lado da Moeda: Histórias Ocultas do Cruzado e da Moratória. São Paulo: Siciliano.

NORDHAUS, W. (1975) “The political business cycle”. Review of Economic Studies, vol. 42, p. 169-190. NORTH, D. C. (1990) Institutions, Institutional Change, and Economic Performance. Cambridge: Cambridge University Press.

NORTH, D. C. (1991) "Institutions". Journal of Economic Perspectives, vol. 5, n. 1, p. 97-112.

NORTH, D. C. (1994) "Economic performance through time". American Economic Review, vol. 84, n. 3, p. 359-367.

NORTH, D. C. (2005) Understanding the Process of Economic Change. Princeton and Oxford: Princeton University Press.

PERSSON, T.; TABELlINI, G. (1990) Macroeconomic Policy, Credibility and Politics. Switzerland: Harwood Academic Publishers.

PERSSON, T.; TABELLINI, G. (1994a) Monetary and Fiscal Policy: Credibility. Cambridge: MIT Press, vol.1.

PERSSON, T.; TABELLINI, G. (1994b) “Designing institutions for monetary stability”. CornegieRochester Conference Series on Public Policy, 39, p. 58-94.

PERSSON, T.; TABELLINI, G. (1995) Monetary and Fiscal Policy: Politics. Cambridge: MIT Press, vol. 2. PINTO, Celi Regina J. (1989) Com a Palavra o Senhor Presidente José Sarney. São Paulo: Hucitec.

PORTELLA FILHO, Petrônio. (1988) Moratória Soberana. São Paulo: Alfa-Omega.

PRESSER, Mário F. (1986) "A renegociação da dívida externa na Nova República”. In Ricardo Carneiro, org. Política Econômica da Nova República. Rio de Janeiro: Paz e Terra.

RESENDE, André L. (1982) “A ruptura no mercado internacional de crédito”. In Persio Arida, org. Dívida Externa, Recessão e Ajuste Estrutural: O Brasil Diante da Crise. Rio de janeiro: Paz e Terra. 
ROGOFF, Kenneth (1990) “Equilibrium political budget cycles”. American Economic Review, vol. 80, n.1, p. 21-36, mar.

ROGOFF, Kenneth; SILBERT, A. (1988) "Elections and macroeconomic policy cycles". Review of Economic Studies, vol. 55, p. 1-16.

SALOMÃO, Ivan C. (2010) "Arroubos econômicos, legitimação política: uma análise da moratória da dívida externa de 1987" Dissertação de mestrado. Universidade Federal do Rio Grande do Sul, Porto Alegre.

SAMPAIO JÚNIOR, Plínio de A.; AFFONSO, Rui. (1986) “A transição inconclusa”. In Flavio Koutzii, org., Nova República: Um Balanço. Porto Alegre: L\&PM.

SOLNIK, Alex (1987). Os Pais do Cruzado Contam Por Que Não Deu Certo. São Paulo: L\&PM.

SOUZA, Nilson A. de. (1986) Na Era do Cruzado. Rio de Janeiro: Gravina.

WEINGAST, B. (2005) "The self-enforcing constitution: with an application to uncertain democracy in America's first century”. Working Paper Hoover Institution.

WEINGAST, B. SHEPSLE, K. e JOHSEN, C. (1981) "The political economy of benefits and costs: a neoclassical approach to distributive politics”. Journal of Political Economy, n. 89, p. 642-644.

WILLIAMSON, Oliver E. (1985) The Economic Institutions of Capitalism. New York: The Free Press. WILLIAMSON, Oliver E. (1993) "Transaction cost economics and organization theory". Industrial and Corporate Change, vol. 2, n. 2, p. 107-156.

WILLIAMSON, Oliver E. (1996) The Mechanisms of Governance. New York and Oxford: Oxford University Press.

WILLIAMSON, Oliver E. (2000) “The new institutional economics: taking stock, looking ahead. Journal of Economic Literature, vol. 38, p. 595-613.

WITTMAN, D. (1989) "Why democracies produce efficient results". Journal of Political Economy, n. 97, p. 1395-1424, 1989.

WITTMAN, D. (1995) The Myth of Democratic Failure: Why Political Institutions are Efficient. Chicago: University of Chicago Press. 